\title{
PENDIDIKAN KESEHATAN TENTANG PHBS TERHADAP PENINGKATAN PENGETAHUAN KADER DI DESA JAYARAGA GARUT
}

\author{
Udin Rosidin ${ }^{1}$, Iwan Shalahuddin ${ }^{2}$, Theresia Eriyani ${ }^{3}$
}

${ }^{1}$ Fakultas Keperawatan Universitas Padjadjaran Bandung Jawa Barat, Indonesia Email: dinr8629@gmail.com

${ }^{2}$ Fakultas Keperawatan Universitas Padjadjaran Bandung Jawa Barat, Indonesia Email: shalahuddin@unpad.ac.id

${ }^{3}$ Fakultas Keperawatan Universitas Padjadjaran Bandung Jawa Barat, Indonesia Email: theresiaeriyani@gmail.com

\section{ABSTRACT: HEALTH EDUCATION ABOUT PHBS AGAINST INCREASED KNOWLEDGE OF CADRES IN JAYARAGA VILLAGE GARUT}

Background: The coverage of clean and healthy living behavior (PHBS) households in West Java is $51.40 \%$. The coverage is in the 12 th position from 33 provinces in Indonesia. The national figure shows $56.58 \%$. If we observe this number, it turns out that the West Java figure is lower than the national figure. Based on the Health Profile of Garut Regency, data was obtained that households that had implemented a new PHBS were $51.70 \%$. One reason is that there is still a low level of public knowledge about PHBS.

Purpose: This study was to determine the effect of health education about PHBS on improving the knowledge of health cadres in understanding household PHBS. Methods: This study is quantitative analytics by comparing the average value of knowledge of respondents before and after educational activities are carried out. The statistical test used was the Wilcoxon test with an error rate of $5 \%$ (alpha $=$ 0.05). The total population is 45 people.

Results: Showed a significant change between before and after health education with $\mathrm{p}$ value; 0.00 . The average pre test value is $46.2(\mathrm{SD} .8,57)$ and post test 67.3 (SD 9.59).

Conclusion: This study is an increase in the average value of respondents' knowledge of 12.50. It is hoped that this research can be an effort to further improve health education about household PHBS.

Keywords: Health Education, PHBS, Household Order, Health Cadre

\section{INTISARI: PENDIDIKAN KESEHATAN TENTANG PHBS TERHADAP PENINGKATAN PENGETAHUAN KADER DI DESA JAYARAGA GARUT}

Pendahuluan: Cakupan rumah tangga berperilaku hidup bersih dan sehat (PHBS) di Jawa Barat sebesar 51,40 \%. Angka cakupan tersebut berada pada posisi 12 dari 33 provinsi di Indonesia. Angka nasional menunjukan sebesar 56,58\%. Apabila kita amati angka tersebut ternyata angka Jawa Barat lebih rendah dari angka nasional. Berdasarkan profil Kesehatan Kabupaten Garut didapatkan data bahwa rumah tangga yang sudah melaksanakan PHBS baru sebesar 51,70\%. Salah satu penyebabnya adalah masih rendahnya pengetahuan masyarakat tentang PHBS. 
Tujuan: Tujuan penelitian ini adalah untuk mengetahui pengaruh pendidikan kesehatan tentang PHBS terhadap peningkatan pengetahuan Kader Kesehatan dalam memahami PHBS Rumah Tangga.

Metode: Metode yang digunakan dalam penelitian ini adalah analitik kuantitatif dengan membandingkan rata rata nilai pengetahuan responden sebelum dan sesudah kegiatan pendidikan dilaksanakan. Uji statistik yang digunakan adalah uji wilcoxon dengan tingkat kesalahan sebesar $5 \%($ alpha $=0,05)$. Jumlah populasi sebanyak 45 orang.

Hasil: Hasil penelitian menunjukan adanya perubahan yang signifikan antara sebelum dan sesudah pendidikan kesehatan dengan $p$ value; 0,00 . Rata rata nilai pre test 46,2 (SD.8,57) dan post test 67.3 (SD 9,59).

Simpulan: Penelitian ini didapatkan adanya peningkatan rata rata nilai pengetahuan responden sebesar 12.50. Diharapkan dari penelitian ini dapat menjadi upaya untuk lebih meningkatkan pendidikan kesehatan tentang PHBS Rumah Tangga.

\section{Kata Kunci : Pendidikan Kesehatan, PHBS Tatanan Rumah Tangga, Kader Kesehatan}

\section{PENDAHULUAN}

Kebijakan pemerintah pusat dalam hal ini Kementerian Kesehatan dengan program PHBS (Perilaku Hidup Bersih dan Sehat) serta program Germas (Gerakan masyarakat Sehat) dan Kementerian Dalam Negeri dengan program Kecamatan Sehat bertujuan agar masyarakat dapat hidup sehat. Kebijakan tersebut didasarkan atas pertimbangan bahwa kemampuan hidup sehat bagi semua penduduk merupakan hak asasi manusia. Sehat juga merupakan prasyarat agar hidup kita menjadi berarti, sejahtera, dan bahagia. Untuk mewujudkan hal tersebut setiap warga negara wajib menjaga, memelihara, melaksanakan dan meningkatkan hidup sehat dengan merubah cara pandang dari paradigma sakit menjadi paradigma sehat.

\section{Dalam}

rangka

mengoperasionalkan paradigma sehat khususnya yang berkaitan dengan promosi kesehatan di Indonesia, Diperlukan upaya upaya peningkatan pemahaman semua unsur di masyarakat tentang Perilaku Hidup Bersih dan Sehat (PHBS)( Irawati, 2011; Nurhajati, 2015). Masyarakat diharapkan dapat melaksanakan PHBS sesuai dengan apa yang tertuang dalam Peraturan Menteri Kesehatan Republik Indonesia Nomor : 2269 / MENKES / PER / XI / 2011. Peraturan tersebut mengatur upaya peningkatan perilaku hidup bersih dan sehat di seluruh Indonesia dengan mengacu kepada pola manajemen PHBS, mulai dari tahap pengkajian, perencanaan, dan pelaksanaan serta pemantauan dan penilaian. Upaya tersebut dilakukan untuk memberdayakan masyarakat dalam memelihara, meningkatkan dan melindungi kesehatannya sehingga masyarakat sadar, mau, dan mampu secara mandiri ikut aktif dalam meningkatkan status kesehatannya. Kita menyadari bahwa upaya tersebut bukanlah suatu hal yang mudah karena upaya tersebut berkaitan sangat erat dengan masalah perilaku. Sedangkan masalah perilaku merupakan masalah yang khas dan kompleks (Taufiq, at al, 2013: Sanyata, 2012) . PHBS dapat diterapkan dalam kehidupan seharihari pada lingkungan sekitar, seperti lingkungan rumah tangga, sekolah, dan tempat kerja. PHBS pada tatanan rumah tangga merupakan bentuk 
perwujudan paradigma sehat dalam budaya hidup perorangan dan keluarga, yang bertujuan untuk meningkatkan, memelihara dan melindungi kesehatannya (Carolina, at al, 2016: Nofriani, 2016).

Cakupan rumah tangga berperilaku hidup bersih dan sehat di Jawa Barat berdasarkan data yang diperoleh dari profil data kesehatan Indonesia tahun 2014 yang dikeluarkan oleh kementerian kesehatan sebesar $51,40 \%$, (Kemenkes RI, 2014). Posisi Jawa Barat berada pada nomor 12 dari 33 provinsi di Indonesia. Apabila kita amati angka tersebut ternyata angka jumlah rumah tangga di Jawa Barat yang melaksanakan PHBS jumlahnya dibawah angka nasional (56,58 \%).

Berdasarkan data yang dikeluarkan oleh Dinas Kesehatan Provinsi Jawa Barat tahun 2014 jumlah rumah tangga yang berperilaku hidup bersih dan sehat di Kabupaten Garut tahun 2011 sebesar $58,20 \%$, tahun 2012 sebesar 33,80\% tahun 2013 sebesar $35 \%$ dan tahun 2014 sebesar 51,70 \%. Dari data tersebut dapat ditarik kesimpulan bahwa masih banyak masyarakat di Kabupaten Garut belum melaksanakan Perilaku Hidup Bersih dan Sehat.

Belum dilaksanakannya PHBS pada masyarakat Garut salah satunya ditentukan oleh rendahnya pengetahuan masyarakat tentang PHBS. Dalam survey awal yang dilakukan di RW 12 Desa Jayaraga Kecamatan Tarogong Kidul Kabupaten Garut didapatkan data bahwa pengetahuan masyarakat tentang PHBS Rumah Tangga kurang dari setengahnya $(43,4 \quad \%)$ mempunyai pengetahuan kurang baik. Upaya peningkatan pengetahuan tersebut perlu dilakukan melalui berbagai cara salah satunya meningkatkan pengetahuan kader kesehatan.
Kader kesehatan merupakan tokoh masyarakat yang akan menjadi panutan dalam pelaksanaan hidup sehat (Rezeki, \& Mulyadi, 2013; Rochmawati, 2010). Agar masyarakat dapat melaksanakan PHBS maka langkah strategis untuk pelaksanaan PHBS diawali dengan tokohnya (Suka, at al, 2013: Widowati, 2013). Berdasarkan permasalahan tersebut maka kami tertarik untuk melakukan penelitian tentang pengaruh pendidikan kesehatan kepada kader sebagai tokoh masyarakat dalam upaya peningkatan pengetahuan PHBS Rumah Tangga di Desa Jayaraga Kecamatan Tarogong Kidul.

\section{METODE}

Metode penelitian yang digunakan dalam penelitian ini adalah analitik kuantitatif dengan membandingkan rata rata nilai pengetahuan responden sebelum dan sesudah kegiatan pendidikan dilaksanakan. Analisis yang digunakan adalah analisis univariat dan analisis bivariat. Analisis univariat digunakan untuk menggambar karakteristik responden melalui distribusi frekuensi sedangkan analisis bivariat menggunakan analiss uji wilcoxon dengan tingkat kepercayaan sebesar $95 \%$ dan tingkat kesalahan sebesar 5 $\%$ ( $a l p h a=0,05)$. Apabila nilai $p$ value lebih kecil dari nilai alpha maka $\mathrm{Ha}$ diterima artinya ada perbedaan rata rata nilai pengetahuan sebelum dan sesudah pendidikan kesehatan dilaksanakan. Responden dalam penelitian ini adalah kader kesehatan dengan jumlah populasi sebanyak 80 orang. sampel sebanyak 45 orang yang diambil dari setiap RW dengan perhitungan rumus Slovin dengan tingkat kesalahan sebesar $10 \%$.

\section{HASIL}

Hasil penelitian ini diawali dengan menyajikan karakteristik responden yang terdiri dari Usia responden, suku bangsa responden, 
pekerjaan responden, pendidikan responden dan lamanya responden menjadi kader. Hasil analisis univariat didapatkan data bahwa usia kader kesehatan yang mengikuti kegiatan pendidikan kesehatan tentang PHBS sebagian besar berusia 41-50 tahun (44,4\%). Hampir seluruh kader kesehatan tidak bekerja atau ibu rumah tangga $(77,8 \%)$. Tingkat pendidikan kader kesehatan sebagian besar adalah SLTA (57,8 \%). Sedangkan pengalaman menjadi kader lebih dari setengahnya menjadi kader selama 1 - 5 tahun (68.9\%). Data selengkapnya dapat dilihat pada tabel 1 berikut ini:

Tabel 1. Distribusi frekuensi karakteristik responden berdasarkan usia, suku bangsa, pekerjaan pendidikan, dan lama menjadi kader kesehatan $(\mathrm{N}=45)$.

\begin{tabular}{lcc}
\hline Variabel & Frequensi & Persentase \\
\hline Usia & 16 & 35,6 \\
$30-40$ tahun & 20 & 44,4 \\
$41-50$ tahun & 9 & 20 \\
$51-60$ tahun & & \\
Suku Bangsa & 40 & 100 \\
Sunda & 0 & 0 \\
Jawa & & \\
Pekerjaan & 35 & 77,8 \\
Tidak bekerja & 0 & 0 \\
Buruh & 3 & 6,7 \\
Pensiun PNS & 7 & 15,5 \\
Wiraswasta & & \\
Pendidikan & 2 & 4,4 \\
SD & 10 & 22,2 \\
SLTP & 26 & 57,8 \\
SLTA & 7 & 15,6 \\
PT & & \\
Lama menjadi kader & 31 & 68,9 \\
1-3 tahun & 6 & 13,3 \\
4-6 tahun & 6 & 13,3 \\
7-10 tahun & 2 & 4,5 \\
$>11$ tahun & &
\end{tabular}

Berdasarkan tabel 1, menunjukan bahwa karakteristik responden hamper sebagian berusia 41-50 sebesar $20 \quad(44,4 \%)$ dengan seluruh responden bersuku bangsa sunda $(100 \%)$, dan hamper seluruhnya tidak bekerja sebesar $35(77,8 \%)$ yang memiliki pendidikan terakhir sebagian besar SLTA sebanyak 26
(57,8\%) serta lamanya menjadi kader hampir sebagian responden memiliki masa waktu 1-3 tahun sebesar 31 $(68,9 \%)$.

Setelah dilakukan analisis dengan uji statistic menggunakan Wilcoxon maka didapatkan data sesuai tabel berikut ini : 
Tabel 2. Hasil Uji Perbedaan Rata-Rata Pengetahuan Kader Kesehatan Sebelum dan Sesudah Pendidikan Kesehatan

\begin{tabular}{lcccc}
\hline Variabel & $\begin{array}{l}\text { Sebelum } \\
\text { M(SD) }\end{array}$ & $\begin{array}{l}\text { Sesudah } \\
\text { M (SD) }\end{array}$ & $\begin{array}{l}\text { Mean } \\
\text { Rank }\end{array}$ & $P$ \\
\hline Pengetahuan & 42.0 & 61,9 & 22.50 & 0.00 \\
& $(8.78)$ & $(12,9)$ & & \\
\hline
\end{tabular}

Berdasarkan tabel 2, menunjukan ada perbedaan yang signifikan pengetahuan kader kesehatan antara sebelum dan sesudah kegiatan pendidikan kesehatan tersebut. Dari data tersebut terlihat bahwa rata rata nilai pretest kader kesehatan tentang PHBS Rumah Tangga adalah sebesar 42,0 dengan standart deviasi sebesar 8,78 . Sedangkan untuk postest rata rata nilainya adalah 61,9 dengan standar deviasi 12,9. Dari data tersebut dapat dilihat bahwa peningkatan pengetahuan rata rata 22,50 . Selain itu juga didapatkan $p$ value sebesar 0,00 sehingga ada perbedaan antara rata rata nilai pengetahuan sebelum dilakukan pendidikan kesehatan dengan rata rata nilai pengetahuan setelah dilakukan pendidikan kesehatan.

\section{PEMBAHASAN}

Rangkaian kegiatan pendidikan kesehatan kepada kader kesehatan di Desa Jayaraga dapat meningkatkan pengetahuan kader kesehatan tentang PHBS Rumah Tangga. Di awal kegiatan, pada saat dilakukan pre test tentang pengetahuan PHBS Rumah Tangga dan hasil pre test sebagian besar kader kesehatan belum mengetahui dan memahami secara jelas tentang PHBS Rumah Tangga.

bahwa rata rata nilai
pengetahuannya sebesar Peserta yang hadir sangat antusias mengikuti kegiatan, karena pendidikan kesehatan tentang PHBS Rumah Tangga merupakan hal yang sangat mendasar untuk pelaksanaan hidup sehat. Pada pelaksanaan pendidikan kesehatan meskipun ada sebagian kader kesehatan di awal kegiatan saat tanya jawab ada beberapa kader kesehatan mampu memaparkan tentang PHBS namun secara keseluruhan kader belum memahami secara jelas tentang PHBS Rumah Tangga. Setelah dilakukan pendidikan kesehatan didapatkan peningkatan rata rata nilai pengetahuan beserta 22,50 point. Adanya informasi tentang PHBS Rumah Tangga yang kader kesehatan dapatkan dalam kegiatan ini menjadikan kader lebih memahami tentang PHBS Rumah Tangga (Damaiyanti \& Hardyanti, 2015; Marzuki, Nurdin, \& Harisnal, 2016; ). Peningkatan pengetahuan kader kesehatan tersebut sangat ditunjang oleh karakteristik kader kesehatan yang dimilikinya seperti umur, tingkat pendidikan, pekerjaan dan lamanya menjadi kader kesehatan (Maulina, 2012: Putri \& Putro, 2015). Hal ini sesuai dengan teori yang dikemukakan oleh Notoatmodjo (2010) bahwa karakteristik: sosial budaya, pengalaman dapat mempengaruhi pengetahuan, keinginan, sikap dan niat seseorang dalam melaksanakan sebuah perilaku (Suharyat, 2009; Saputra, \& Mulasari, 2017).

Perilaku Hidup Bersih dan Sehat (PHBS) adalah semua perilaku yang dilakukan atas kesadaran sendiri sehingga dapat menolong dirinya sendiri di bidang kesehatan dan berperan aktif dalam kegiatankegiatan kesehatan. Untuk dapat melakukan perilaku tersebut sangatlah diperlukan adanya 
pengetahuan yang mendukung terhadap pelaksanaan PHBS. Menurut teori L. Green (1990) dalam Notoatmodjo (2010) perilaku pelaksanaan PHBS tersebut akan ditentukan oleh banyak faktor yaitu predisposing factor, enabling factor dan reinforcing factor. Pada Predisposing factors seperti faktor pengetahuan, sikap, kepercayaan dan keyakinan responden terhadap PBHS. Enabling factors adalah akses responden ke pelayanan kesehatan dan ketersediaan sarana. Sedangkan reinforcing factors adalah perilaku petugas kesehatan dan perilaku tokoh masyarakat (Saputro, 2017; Ringga, 2017)

Peningkatan pengetahuan dan pemahaman kader kesehatan tentang PHBS Rumah Tangga membawa perubahan yang signifikan terhadap sikap kader kesehatan dalam memahami PHBS. (Nurazizah, 2010; Karim, 2018). Pengetahuan dan sikap kader kesehatan tersebut diharapkan dapat menjadi dasar upaya peningkatan pelaksanaan PHBS di Desa Jayaraga.

\section{SIMPULAN}

Berdasarkan hasil penelitian dan pembahasan tersebut diatas maka pendidikan kesehatan sangat berpengaruh terhadap peningkatan pengetahuan kader kesehatan tentang PHBS Rumah Tangga. Pendidikan kesehatan membawa dampak yang signifikan dalam mendasari pengetahuan dan pemahaman kader kesehatan mengenai PHBS Rumah Tangga. Kader kesehatan sebagai tokoh masyarakat dibidang kesehatan dan sebagai ujung tombak penggerak kesehatan di masyarakat dapat menjadi contoh dan panutan dalam upaya untuk meningkatkan Pelaksanaan PHBS Rumah Tangga di Desa Jayaraga.

\section{SARAN}

Perlu adanya optimalisasi peran kader kesehatan dalam beberapa kegiatan kesehatan yang berbasis masyarakat. Sehingga seluruh pelayanan kesehatan yang ada dimasyarakat dapat tersosialisasikan dengan baik. Rencana tindak lanjut dari penelitian ini adalah tindak lanjut kegiatan yang dilaksanakan oleh kader kesehatan kepada masyarakat

\section{DAFTAR PUSTAKA}

Carolina, P., Carolina, M., \& Lestari, R. M. (2016). Hubungan tingkat pengetahuan dan sumber informasi dengan penerapan perilaku hidup bersih dan sehat (phbs) pada keluarga di wilayah kerja pustu pahandut seberang kota palangka raya tahun 2016. EnviroScienteae, 12(3), 330-337.

Damaiyanti, S., \& Hardyanti, C. (2015). Hubungan

Pengetahuan Ibu Rumah Tangga Dan Peran Kader Dengan Perilaku Hidup Bersih Dan Sehat (Phbs) Dalam Rumah Tangga Di Kelurahan Laing Wilayah Kerja Puskesmas Nan Balimo Kecamatan Tanjung Harapan Kota Solok Tahun 2014. 'AFIYAH, 2(1).

Departemen Kesehatan RI. (2004). Sistem Kesehatan Nasional.

Dinas Kesehatan Kabupaten Garut. (2015). Pembangunan Kesehatan Kabupaten Garut tahun 2010-2014. 


\section{Irawati, E. (2011). Gambaran Karakteristik Keluarga Tentang Perilaku Hidup Bersih dan Sehat (PHBS) Pada Tatanan Rumah Tangga di Desa Karangasem Wilayah Kerja Puskesmas Tanon II Sragen. Gaster: Jurnal Kesehatan, 8(2), 741-749.}

Jenita. D. (2016). Metodologi Penelitian Keperawatan, Yogyakarta, Pustaka Baru Pers.

Karim, D. S. P. (2018). Determinan Perilaku Hidup Bersih dan Sehat (PHBS) Tatanan Rumah Tangga. Jurnal Ilmu Kesehatan Masyarakat, 7(01), 1-9.

Ketut. S. (2014). Keperawatan Kesehatan Komunitas, Yogyakarta, Andi Offset.

Kementrian Kesehatan RI. (2012). Rencana Strategis Kementrian Kesehatan 2010-2014.

Marzuki, A., Nurdin, N., \& Harisnal, H. (2016). Manajemen penerapan perilaku hidup bersih dan sehat (phbs) tatanan rumah tangga di kelurahan kurao pagang padang. Jurnal Endurance: Kajian Ilmiah Problema Kesehatan, 1(3), 121-135.

Maulina, A. S. (2012). Identifikasi Partisipasi Masyarakat Dalam Pemilahan Sampah Di Kecamatan Cimahi Utara Serta Faktor Yang Mempengaruhinya. Journal of Regional and City Planning, 23(3), 177-196.

Nofriani, M. (2016). Faktor-Faktor Yang Berhubungan Dengan
Penerapan Phbs Di Tatanan Rumah Tangga Di Wilayah Kerja Puskesmas IV Koto Mudik Kecamatan Batang Kapas Kabupaten Pesisir Selatan Tahun 2016 (Doctoral dissertation, UNIVERSITAS ANDALAS).

Nurazizah, R. (2010). Hubungan Presepsi dan Motivasi Kader Kesehatan dengan Kinerja dalam Desa Siaga Program Perencanaan Persalinan dan Pencegahan Komplikasi (P4K) (Doctoral dissertation, Tesis di terbitkan. Surakarta: Program Pasca Sarjana Universitas Sebelas Maret, 19).

Nurhajati, N. (2015). Perilaku hidup bersih dan sehat (PHBS) masyarakat Desa Samir dalam meningkatkan kesehatan masyarakat. Jurnal Publiciana, 8(1), 107-126.

Putri, A., \& Putro, H. (2015). Kajian Hubungan Faktor-faktor yang Membentuk Perilaku Masyarakat Terhadap Pola Pembuangan Sampah di Luwuk. Jurnal Perencanaan Wilayah dan Kota, 4(2), 41927.

Rezeki, S., \& Mulyadi, A. (2013). Strategi Promosi Kesehatan Terhadap Peningkatan Perilaku Hidup Bersih dan Sehat Individu Pada Masyarakat Perkebunan di Wilayah Puskesmas Sei Kijang Kabupaten Pelalawan. Jurnal Ilmu Lingkungan, 7(1), 38-48.

Rochmawati, A. (2010). Hubungan Antara Keaktifan Kader Kesehatan Dengan Pengembangan Program Desa 
Siaga Di Kecamatan Masaran Kabupaten Sragen (Doctoral dissertation, Universitas Sebelas Maret).

Ringga, R. P. (2017). Faktor Dominan Yang Mempengaruhi Perilaku Hidup Bersih Dan Sehat (Phbs) Pada Tatanan Rumah Tangga Permukiman Di Wilayah Kerja Puskesmas Andalas Kota Padang (Doctoral dissertation, Universitas Andalas).

Sanyata, S. (2012). Teori dan aplikasi pendekatan behavioristik dalam konseling. Jurnal Paradigma, 14(7), 1-11.

Saputra, S., \& Mulasari, S. A. (2017). Pengetahuan, Sikap, dan Perilaku Pengelolaan Sampah pada Karyawan di Kampus. Jurnal Kesehatan Masyarakat, 11(1), 22-27.

Saputro, D. P. (2017). Factors Affecting Clean and Healthy Life Behavior at Home of RW 03 Kelurahan Pakunden Blitar City. Jurnal Ners dan Kebidanan, 3(3), 207-212.

Sarvasti. (2012). Penyakit Jantung Dan Pembuluh Darah Penyebab UtamaKematian Dt
Dunia, RSU Husada Utama Surabaya

Suharyat, Y. (2009). Hubungan antara sikap, minat dan perilaku manusia. Jurnal Region, 1(3), 1-19.

Suka, I. G., Muninjaya, A. A. G., Wiasti, N. M., Dewi, A. A. S., \& Aryastami, N. K. (2013). Pemberdayaan Perarem untuk Menurunkan Angka Hamil di Luar Nikah dan Kawin Usia Muda di Desa Pengotan Kabupaten Bangli (Empowering of Perarem to Decreace Pre Marital and Early Married at the Pengotan Village, Bangli District, Bali Province). Buletin Penelitian Sistem Kesehatan, 16(3 Jul).

Taufiq, M., Nyorong, M., \& Riskiyani, S. (2013). Gambaran Perilaku Hidup Bersih dan Sehat (PHBS) Masyarakat di Kelurahan Parangloe Kecamatan Tamalanrea Kota Makassar.

Widowati, T. T. (2013). Perancangan Buku Pop Up Sebagai Media Promosi Kesehatan Gigi, Mulut Dan Kulit Tangan Untuk Anak Usia Pra Sekolah Oleh Dinas Kesehatan Kabupaten 